\title{
Estimating cover of benthic organisms from underwater video images: variability associated with multiple observers
}

\author{
R. Ninio, S. Delean, K. Osborne, H. Sweatman* \\ Australian Institute of Marine Science, PMB No. 3, Townsville, Queensland 4810, Australia
}

\begin{abstract}
Using trained observers and video images of reef transects from many parts of the Great Barrier Reef, we investigated (1) accuracy of classification of benthos and (2) variability contributed by observers to the precision of estimates of benthic cover obtained from video tapes. In order to estimate accuracy of identification, benthic organisms were identified twice, first in the field and later from video images. These identifications were then compared. The effect of observer error on precision of benthic cover estimates was examined by having 2 observers sample the same video images on 3 separate occasions. These estimates were then compared at the level of different benthic groups (hard coral, soft coral and algae) and for different hierarchical levels of classification of hard corals (life form, family, genus and species). 'Benthic groups' (mean accuracy of $90 \pm 8 \%$ ) and 'families of hard coral' $(91 \pm 7 \%)$ were identified most accurately and least variably from video images, although many genera and some distinctive species were also identified reliably. Life forms of hard corals proved to be the least accurate and most variable level of classification, with a mean accuracy rating of $74 \pm 16 \%$. There was little additional variation in estimates of cover when 2 trained observers sampled images, compared with variation in estimates of cover from repeated samples of images by a single observer. At $10 \%$ cover, variability in estimates made by a single observer resulted in mean CIs of 7.9 to $12.1 \%$. Inclusion of variation between observers expanded CIs by only $\pm 0.22 \%$. Furthermore, total observer error was small relative to estimates of cover. For example, at $30 \%$ cover, the mean CI due to both between- and within-observer variability was 27.2 to $32.8 \%$.
\end{abstract}

KEY WORDS: Coral reef · Benthic cover · Underwater video · Observer error · Great Barrier Reef Resale or republication not permitted without written consent of the publisher

\section{INTRODUCTION}

Coral reefs throughout much of the world are in decline, or their status is uncertain (Wilkinson 2000). In response, many countries have initiated monitoring programs that document changes in reef communities by making observations at regular intervals (Dahl 1977, Oliver et al. 1995). Such programs aim to provide a basis for management decisions to promote the long-term survival of reef ecosystems.

Various methods have been used to assess benthic communities on coral reefs, including photo-quadrats (Connell 1978, Done 1981, Hughes 1994), line-intercept transects (English et al. 1997) and video transects (Leonard \& Clark 1993, Aronson \& Swanson 1997). One common application of the latter method uses a video camera to record the benthos along belt transects of fixed length and width. Percent cover of the various organisms is then estimated from the video images using a point-sampling method (Carleton \& Done 1995). Video transects have become popular because they allow a wide swathe of benthos to be recorded in a single pass of the video camera. The method minimises the time spent sampling underwater, thus reducing costs, and can be undertaken by field staff without expertise in the identification of benthic taxa.

Despite increased use of video transects, only a few sources of error associated with the method have been examined. Davidson (1997) measured errors caused by small differences in the placement of video transects 
along fixed survey lines, and also the relationship between sampling effort and the reliability of estimates of percent cover of corals. Many other potential sources of error remain unquantified. For example, an observer's ability to identify benthic organisms accurately may be affected by their familiarity with benthic communities in different regions, or by variation in the quality of video images from different environments. Long-term programs will have staff changes, so several observers will sample the video images over time. Training can reduce differences in the ability to identify benthic organisms from video images, but some will occur even among experienced observers: a single observer's perception will change through time with increasing experience and skills in identification. All inconsistencies in identification among observers and by the same observer over time contribute to 'observer error'.

The magnitude of observer error may depend on the level of classification. Cover estimates of benthic organisms classified into broad categories such as 'hard coral', 'soft coral' and 'algae' were not different among observers, even when observers were relatively inexperienced (Carleton \& Done 1995). However, finer taxonomic resolution requires a greater level of skill, and provides more opportunity for mistakes. Less abundant organisms may be less familiar, and so more readily misidentified, than common taxa, leading to variability in estimates of cover of these organisms by different observers.

Here, we investigate the importance of inter- and intra-observer variability in the identification and estimation of cover of benthic organisms from video images. Firstly, we evaluate classification errors associated with using underwater video by comparing identifications made in the field with those from video images. The following questions were examined: (1) Is there a relationship between accuracy of identification from video images, and abundance of benthic organisms in the field? (2) Does accuracy of identification of benthic organisms vary among regions of the Great Barrier Reef (GBR)? (3) Does accuracy of identification of benthic organisms vary among levels of classification and among categories within these levels?

Secondly, we evaluated the variation in estimates of percent cover (A) when different observers sampled the same video images (between-observer variation) and (B) when observers repeatedly sampled the same video images (within-observer variation). The following questions were examined: (4) Is there a relationship between the abundance of benthic organisms and variability in estimates of percent cover by multiple observers? (5) How much do estimates of percent cover vary between observers and among repeated samples by the same observer? (6) How much do estimates of percent cover vary within and among levels of classification of benthic organisms?

\section{MATERIALS AND METHODS}

We used data from the Australian Institute of Marine Science (AIMS) Long-Term Monitoring Program (LTMP), which involves annual surveys of approximately 50 reefs spread over $10^{\circ}$ latitude on the GBR

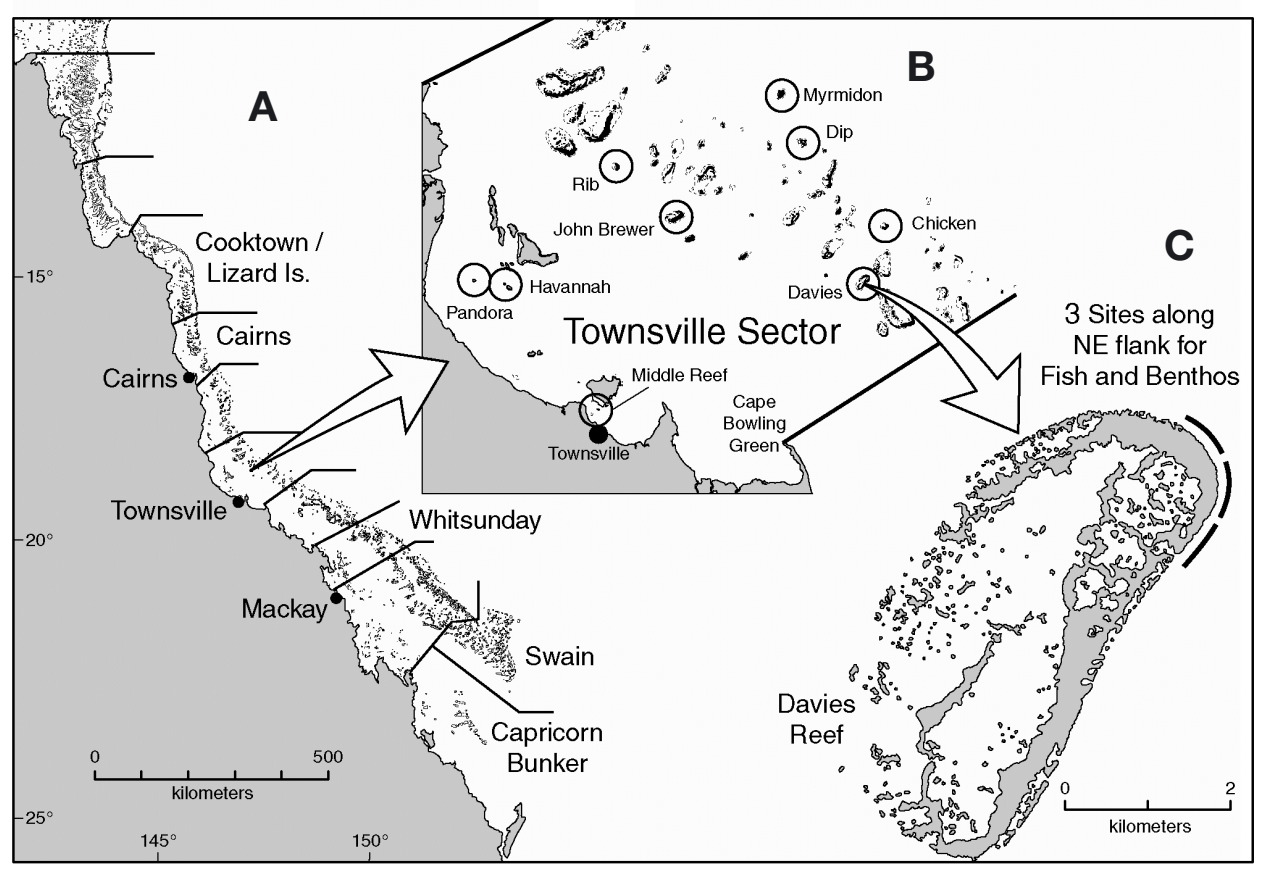

Fig. 1. Location map showing: (A) sectors sampled by the study; (B) cross-shelf distribution of sample reefs (circled) in Townsville sector. Inner: Havannah, Pandora and Middle; mid: Rib, John Brewer and Davies; outer: Myrmidon, Dip and Chicken; and (C) distribution of sites on a single reef. Re-drawn from Ninio et al. (2000) 
made by full-time professional staff. Three sites were sampled at each reef. At each site, $5 \times 50 \mathrm{~m}$ transects were recorded on video (Fig. 1). Transects were fixed by permanent markers (see Sweatman et al. 2000 for details of the LTMP).

A $30 \mathrm{~cm}$ wide swathe was recorded along each $50 \mathrm{~m}$ transect using a video camera held 25 to $30 \mathrm{~cm}$ above the substrate. Percent cover of corals and other benthic organisms was estimated using a point sampling method: approximately 200 systematically dispersed points were sampled from each video transect (Page et al. 2001). The organism lying beneath each point was identified to the most detailed taxonomic or descriptive classification possible, depending on the resolution of the video image and the skill of the observer. We will refer to 5 levels of classification: benthic group, life form (English et al. 1997), family, genus and species (Table 1). Each level is made up of 'categories' that include one or more species of benthic organism (Table 1).

New observers are trained to identify benthic organisms in video transect images by sampling 1 transect from an inshore reef, 1 from a mid-shelf reef and 1 from an offshore reef. Observers must obtain agreement from experienced observers on the identity of organisms beneath $90 \%$ of points. See Page et al. (2001) for more detail.

Accuracy of identification of benthos. To assess accuracy of identification of benthic organisms from the video transects, 10 colour-coded markers were placed at $\sim 5 \mathrm{~m}$ intervals along 1 transect at each of the sites surveyed by the LTMP in the 1998/99 field season. The organisms beneath each marker were identified in situ by a field observer and they also appeared in the video record of that transect. Marked organisms were only included in analyses if the field observers were confident of their identity. In order to assess the accuracy of field identifications, approximately 100 out of a total of 1068 samples were identified in the field by $>1$ observer. There were no differences among observers for those 100 samples.

Up to 4 different observers identified each individual 'marked' organism from a video image. Accuracy of identification was taken as the number of observers that agreed with the field identification out of the total number of observers that attempted to identify that organism to the required level of classification. This was only calculated if (1) an observer identified the organism correctly at coarser levels of classification and (2) that taxon had been recorded more than 10 times in the field. For example, an image of an individual coral would only be used to estimate accuracy of identification to life form and family after it had been placed correctly in the benthic group 'hard coral'.
Table 1. Accuracy of identification (\%) of benthic organisms. $\mathrm{N}=$ sample size. Acr: Acroporidae; Fav: Faviidae; Mer: Merulinidae; Mus: Mussidae; Oc: Oculinidae; Poc: Pocilloporidae; Por: Poritidae; Sid: Siderastreidae

\begin{tabular}{|c|c|c|}
\hline Classification level & $\mathrm{N}$ & Accuracy (\%) \\
\hline \multicolumn{3}{|l|}{ Benthic group } \\
\hline Soft coral & 146 & 92.5 \\
\hline Algae & 147 & 80.6 \\
\hline Hard coral & 775 & 96.0 \\
\hline \multicolumn{3}{|l|}{ Family } \\
\hline Acroporidae & 310 & 96.3 \\
\hline Agariciidae & 22 & 81.9 \\
\hline Faviidae & 151 & 96.8 \\
\hline Fungiidae & 12 & 88.6 \\
\hline Merulinidae & 26 & 93.9 \\
\hline Mussidae & 31 & 96.1 \\
\hline Oculinidae & 22 & 90.5 \\
\hline Pectiniidae & 19 & 96.5 \\
\hline Pocilloporidae & 62 & 95.9 \\
\hline Poritidae & 90 & 89.9 \\
\hline Siderastreidae & 17 & 75.8 \\
\hline \multicolumn{3}{|l|}{ Genus } \\
\hline Acropora (Acr) & 233 & 99.2 \\
\hline Isopora spp. (Acr) & 13 & 87.6 \\
\hline Montipora (Acr) & 64 & 83.8 \\
\hline Cyphastrea (Fav) & 13 & 77.3 \\
\hline Echinopora (Fav) & 23 & 94.8 \\
\hline Favia (Fav) & 43 & 82.8 \\
\hline Favites (Fav) & 20 & 68.8 \\
\hline Goniastrea (Fav) & 18 & 80.3 \\
\hline Platygyra (Fav) & 16 & 49.5 \\
\hline Hydnophora (Mer) & 14 & 88.5 \\
\hline Merulina (Mer) & 11 & 97.0 \\
\hline Lobophyllia (Mus) & 13 & 97.9 \\
\hline Symphyllia (Mus) & 15 & 96.1 \\
\hline Galaxea (Oc) & 20 & 87.9 \\
\hline Pocillopora (Poc) & 37 & 95.8 \\
\hline Seriatopora (Poc) & 12 & 93.6 \\
\hline Stylophora (Poc) & 13 & 100.0 \\
\hline Porites (Por) & 71 & 90.8 \\
\hline Goniopora (Por) & 19 & 82.1 \\
\hline Psammocora (Sid) & 10 & 69.1 \\
\hline \multicolumn{3}{|l|}{ Life form } \\
\hline Branching Acropora & 41 & 65.0 \\
\hline Digitate Acropora & 33 & 88.1 \\
\hline Encrusting Acropora & 10 & 41.3 \\
\hline Corymbose Acropora & 18 & 35.5 \\
\hline Submassive Acropora & 11 & 67.5 \\
\hline Tabulate Acropora & 115 & 85.3 \\
\hline Branching non-Acropora & 41 & 79.4 \\
\hline Encrusting non-Acropora & 163 & 72.2 \\
\hline Foliose non-Acropora & 57 & 83.9 \\
\hline Massive non-Acropora & 169 & 85.4 \\
\hline Submassive non-Acropora & 101 & 79.3 \\
\hline
\end{tabular}

Scatter-plot smoothers were used to examine the relationship between the accuracy of identification and abundance of benthos since these allow for nonlinearities. These local-regression smoothers used the loess fitting method (Hastie \& Tibshirani 1990). A generalised linear model (McCullagh \& Nelder 1989) with 
logit link and binomial variance functions was used to examine differences in the proportion of correct identifications among different categories within each level of classification. The statistical model included terms to account for predictable sources of variation in the proportion of correct identifications. These were: variation among samples from inshore, mid-shelf or outer-shelf areas for each sector (termed 'regions') and among reefs within the regions. The model used to estimate the proportion of correct identification $(y)$ for each category among regions was:

$$
\log \left(y_{\mathrm{ijk}} /\left[1-y_{\mathrm{ijk}}\right]\right)=\mu+S_{\mathrm{i}}+r_{\mathrm{j}}\left(S_{\mathrm{i}}\right)+C_{\mathrm{k}}+\varepsilon_{\mathrm{ijk}}
$$

where $\mu=$ the overall mean, $s=$ region $(\mathrm{i}=1, \ldots, \mathrm{p}), r=$ reefs $(\mathrm{j}=1, \ldots, \mathrm{m}), \mathrm{c}=$ categories $(\mathrm{k}=1, \ldots, \mathrm{l})$ and $\varepsilon_{\mathrm{ijk}} \sim \operatorname{binomial}[0, y(1-y) / n]$. Categories and regions were treated as 'fixed' and reefs were random replicates within regions. Region effects were tested against reef within region effects, while all other terms were tested against the error. The proportions of correct identifications were weighted by the number of observers that attempted to identify each marked organism. Not all categories within each level of classification were recorded in all regions. Given that there was no evidence that different categories of organisms were identified with varying accuracy in different regions, regional variation was pooled with the error variance. Regional variation in accuracy of identification to species was not investigated because organisms identified to this level were sparsely distributed among regions. Sequential $F$-tests were used to examine the contribution of terms to the model.

The statistical model estimated mean probability of correct identification for each category within each level of classification. These estimates were then used to assess (1) differences in the mean accuracy of identification for different categories, and (2) variation in accuracy of identification among classification levels.

Variability in the precision of estimates among observers. One video transect was selected from each of 15 reefs that were surveyed in the 1998/99 summer field season. These transects covered a range of reef topographies including steep walls, fields of bommies (steep-sided patch reefs) and gentle slopes. Because our analysis was based on single transects from each chosen reef, differences among these transects reflected differences among the reefs. Therefore, we refer to these sampling units as 'reefs'.

The video images of each transect were sampled by 2 observers on each of 3 separate occasions. Repeat samples by the same observer were made at least $1 \mathrm{yr}$ apart, during which time they had sampled at least 400 other transects. A time-code on each frame enabled observers to sample exactly the same points each time. Observers identified the organism beneath each sample point on the video image to the finest level of classification possible. These data were used to calculate the percent cover of each category of benthos. Consistency of identification at the different levels of classification was assessed from the frequency with which observers agreed on the presence or absence of the categories of benthos.

A linear mixed-model (Pinheiro \& Bates 2000) was used to calculate components of variance in percent cover of more abundant organisms (i.e. those with $>5 \%$ cover on at least one reef). The model used to estimate mean percent cover $(y)$ on reefs was:

$$
y_{\mathrm{ijk}}=\mu+r_{\mathrm{i}}+o_{\mathrm{j}}+r O_{\mathrm{ij}}+t_{\mathrm{k}}\left(o_{\mathrm{j}}\right)+\varepsilon_{\mathrm{ijk}}
$$

where $r=$ reefs $(\mathrm{i}=1, \ldots, \mathrm{p}), o=$ observers $(\mathrm{j}=1, \ldots, \mathrm{m})$, and $t=$ repeated sampling occasions $(\mathrm{k}=1, \ldots, \mathrm{l})$ and $\varepsilon_{\mathrm{ijk}} \sim \operatorname{Normal}\left(0, \sigma^{2}\right)$. Reefs were treated as fixed, as our aim was to determine differences in estimates of cover among these reefs. Terms for differences between observers and differences among repeated sampling occasions for each observer were represented as random sources of variation in the model.

The random components of variance were estimated for the percent cover of each category within each level of classification. The model estimated the mean percent cover on each reef, random variance in estimates of cover due to differences between observers $\left(o_{\mathrm{j}}\right)$, differences between observers among reefs (the interaction $r \mathrm{O}_{\mathrm{ij}}$ ), differences among repeated sampling occasions by each observer $\left(t_{\mathrm{k}}\left[o_{\mathrm{j}}\right]\right)$ and the residual variance $\left(\varepsilon_{\mathrm{ijk}}\right)$. The components of variance were estimated using restricted maximum likelihood.

The estimated variance components were used to calculate the SD (i.e. the precision) of (1) percent cover on a reef by a given observer, $\sqrt{ }\left(\sigma_{t(o)}^{2}+\sigma_{\varepsilon}^{2}\right)_{i}(2)$ percent cover on a reef by different observers, $\sqrt{ }\left(\sigma_{o}^{2}+\sigma^{2}{ }_{o r}+\right.$ $\left.\sigma^{2}{ }_{t(o)}+\sigma_{\varepsilon}^{2}\right)_{i}(3)$ differences in estimates of percent cover among reefs by a single observer, $\sqrt{ }\left(2 \sigma^{2}{ }_{o r}+2 \sigma^{2}{ }_{t(o)}+\right.$ $\left.2 \sigma_{\varepsilon}^{2}\right)$; and (4) differences in estimates of percent cover among reefs by different observers, $\sqrt{ }\left(2 \sigma^{2}{ }_{\text {or }}+2 \sigma^{2}{ }_{\text {or }}+\right.$ $2 \sigma_{t(o)}^{2}+2 \sigma_{\varepsilon}^{2}$ ). The SD from (1) represented withinobserver (or intra-observer) variability, while the standard deviation from (2) represented total observer error, which included between-observer (or interobserver) and within-observer variability. Variance components were multiplied by 2 to give the SD of estimates of percent cover by different observers and between different reefs.

Variation in cover increased with increasing mean values of cover for all categories within all classification levels. A square-root transformation of percent cover stabilised the mean-variance relationship and was used as the response in all cases. As a result, the precision of estimates of cover on the raw scale varied 
depending on the particular value of cover. To present the precision of estimates of cover, confidence intervals for the transformed data were back-transformed to the raw scale.

\section{RESULTS}

\section{Accuracy of identification of benthic organisms from video images}

Relationship between accuracy of identification and abundance in the field

A total of 1068 benthic organisms were identified in the field, consisting of 775 hard corals, 146 soft corals and 147 algae. There was no obvious relationship between the accuracy of identification and the abundance of any level of classification of hard corals (Fig. 2, Table 1), although accuracy of identification of life forms decreased at very low abundances (Fig. 2).

Accuracy of identification among regions of the GBR

There was no strong evidence for regional differences in accuracy of identification of life forms, families, genera or species. There was some suggestion of differences among regions in accuracy of identification of benthic groups $\left(F_{14,1037}=1.67, \mathrm{p}=0.056\right)$.

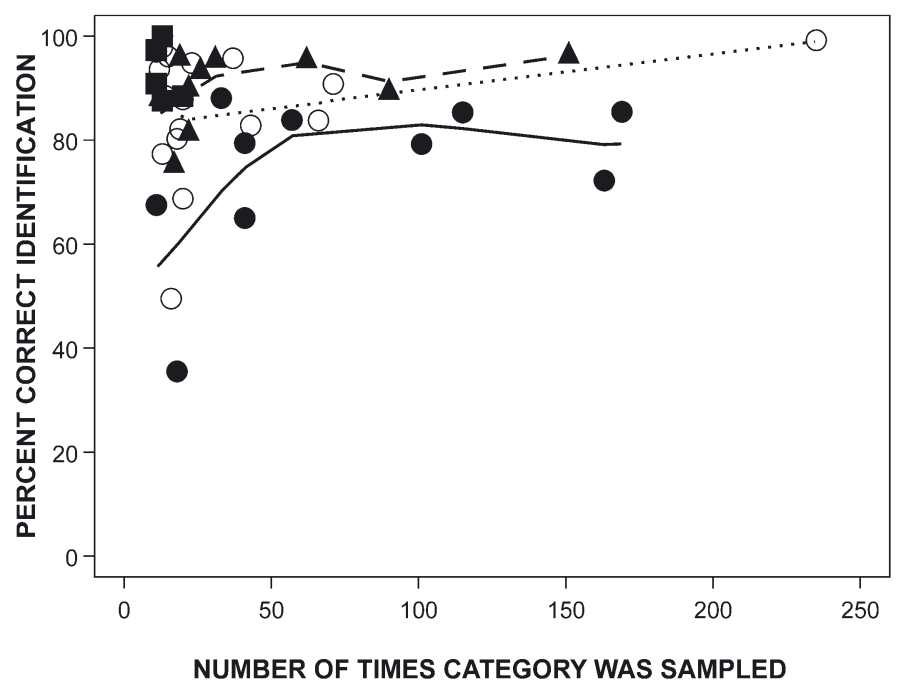

Fig. 2. Relationship between the number of times each category of hard coral was sampled in situ and percent correctly identified from video images. Categories of life form $(\bullet)$,

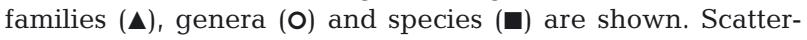
plot smooths are shown for life form $(-)$, family $(---)$, and genus $(\cdots \cdot)$
Accuracy of identification among levels and among categories of classification

There were significant differences among categories within each classification level in the accuracy of identification (Table 1) among benthic groups $F_{2,1005}=$ 26.76, $\mathrm{p}<0.0001)$, among life form categories $\left(F_{9,693}=\right.$ $6.38, \mathrm{p}<0.0001)$, among families $\left(F_{10,648}=2.15, \mathrm{p}=\right.$ $0.019)$, among genera $\left(F_{17,548}=5.12, \mathrm{p}<0.0001\right)$, and among species $\left(F_{5,66}=30.29, \mathrm{p}<0.0001\right)$.

Accuracy of identification among levels of classification

Among the 'benthic groups', hard corals (96.0 \pm $0.41 \%)$ and soft corals $(92.5 \pm 0.79 \%)$ were identified most accurately (Table 1). Identification of algae was less accurate, with a mean of $80.6 \pm 1.6 \%$. For hard corals, identification to family was the least variable level of classification, with accuracy ranging from $97 \%$ for the Faviidae to $76 \%$ for the Siderasteriidae (Table 1). The median accuracy of identification for families was $94 \%$ (Fig. 3). Identifying hard corals to genera did not reduce the median accuracy of identification substantially, but estimates of accuracy within this level of classification ranged from $100 \%$ for the genus Stylophora to $50 \%$ for Platygyra (Table 1, median $89 \%, \mathrm{n}=18$, Fig. 3). Classification to species was relatively accurate (median $90 \%, \mathrm{n}=5$ ), with little variation among categories, but only a few distinctive corals could be identified to this level. Accuracy ranged from $100 \%$ for $S$. pistillata to $88 \%$ for Isopora spp. (Table 1, Fig. 3). In contrast, identifying hard corals to life form was the least accurate and most vari-

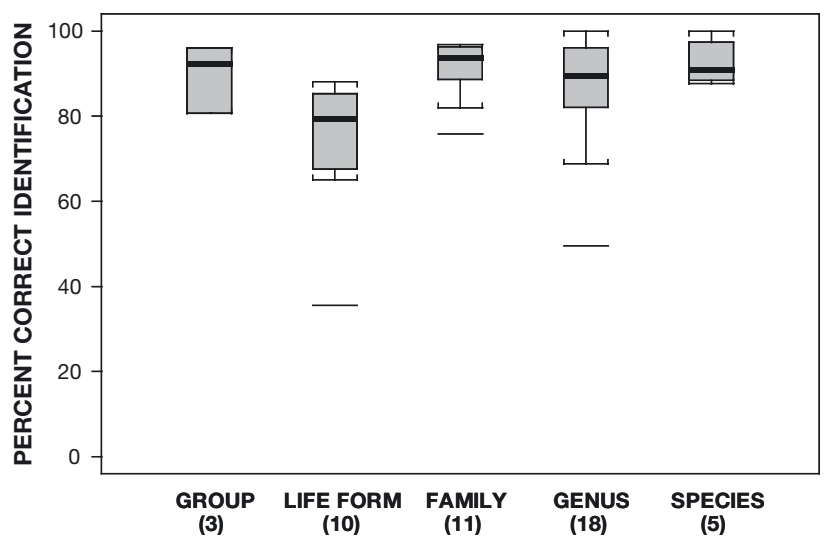

Fig. 3. Distribution of percent of correctly identified organisms among categories of benthic group, life form, family, genus and species. Box plots show the median (solid line) and the 25th to 75th percentiles (boxes), and the whiskers encompass all points within 1.5 times the inter-quartile range. Outliers are indicated by single lines. Numbers in parentheses: number of categories within each classification level 
able level of classification. Median accuracy at this level was $79 \%$ and ranged from $88 \%$ for the 'digitate Acropora' to $36 \%$ for the 'corymbose Acropora' (Table 1, Fig. 3).

\section{Observer error in the precision of estimates of percent cover of benthos}

Relationship between abundance and variability in estimates of percent cover

While a few categories such as hard coral, algae and Acropora were abundant on reefs throughout the GBR, cover of many categories was always low. Likewise, some categories occurred on all reefs, while others were only observed on a single reef. We used 2 measures of variability in assessments of the benthic community on each reef. First, we counted the instances when observers agreed that a category of organisms was present or absent on each occasion that reefs were sampled. Secondly, we calculated the precision of abundance estimates for all taxa.

For benthic groups, both observers agreed on each group's presence/absence on all reefs in all years. If the mean cover of a genus of hard coral was more than $1 \%$ of total cover ( $\geq 2$ points per reef), nearly all observers recorded it in each re-sampling of the same video image. Of the 20 genera whose mean cover on reefs exceeded $1 \%, 17$ were recorded by both

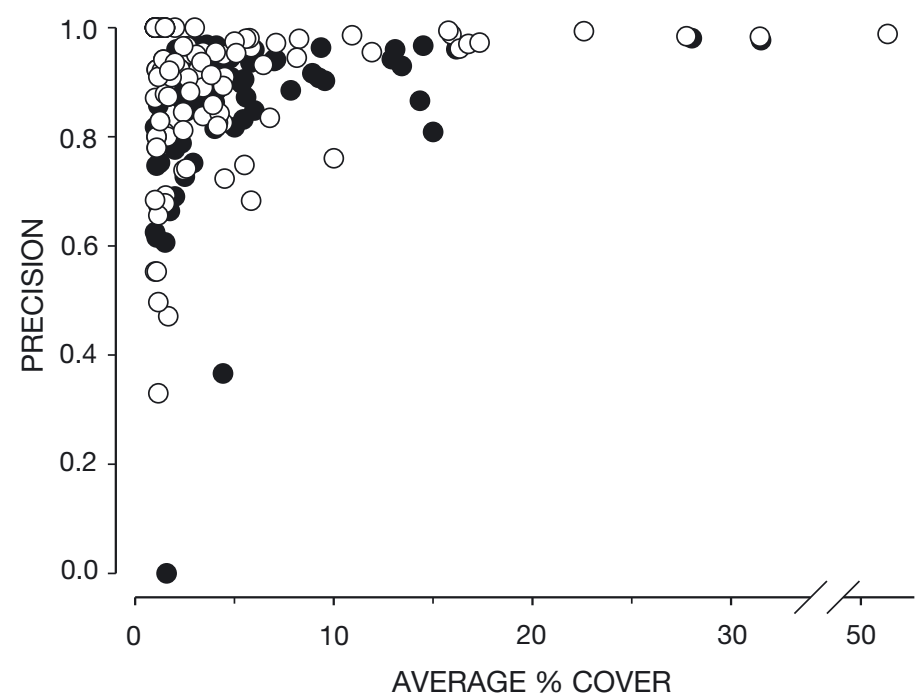

Fig. 4. Relationships between mean percent cover and precision of percent cover estimates for life forms and genera. Estimates of precision of percent cover estimates on each reef were calculated using the formula: 1 - (SE of cover among estimates/mean cover). Categories within the level of life form (@) and categories within the level of genus (O) are shown observers in all 3 samples of the video images. Observers did not record the presence of a given genus consistently when cover was very low. This relationship did not hold for the life form classification: at mean cover values of $\geq 1 \%$, observers agreed on the presence of only 7 of the 12 life forms. Precision was highly variable when mean cover on reefs was less than $3 \%$, but variability decreased markedly with increasing mean cover (Fig. 4).

Observer-related variability of percent cover estimates, and variability within and among levels of classification

The added component of variance in cover estimates due to differences between observers was very small in comparison to that due to repeated sampling by a single observer (Fig. 5). This was true for all categories within all levels of classification. This means that estimates of cover on a given reef at 2 times based on assessments by 2 observers were only slightly less precise than 2 estimates by a single observer (Table 2). When benthic groups had mean cover of $10 \%$, variability in estimates made by a single observer resulted in mean CIs from 8.8 to $11.2 \%$. When between-observer variability was included, confidence intervals were expanded by only $\pm 0.2 \%$. This was due largely to discrepancies in identification of algae: when absolute cover of the benthic group 'Algae' was $10 \%$, variation between observers resulted in confidence intervals that were greater by $\pm 0.5 \%$ (8.1 to $12.1 \%)$. Variation between observers also added very little to overall variation for family and life form levels (means of \pm 0.01 and $\pm 0.2 \%$ at $10 \%$ cover, respectively). The family Mussidae and the genera Lobophyllia and Montipora showed the largest betweenobserver component of variance (Fig. 5). Overall, variation between observers was very small and accounted for only ca. 1/10 of total observer error (Table 2).

In general, observer error was small relative to absolute cover (Fig. 6). At a mean cover of $10 \%$, observer error resulted in confidence intervals that ranged from 9 to $11 \%$ in the category 'hard coral' to limits of 5.1 to $14.9 \%$ for 'digitate Acropora' (Fig. 6). Observer error decreased proportionally with increasing cover, so that at low cover $(10 \%)$, mean confidence intervals among categories were approximately 8.1 to $11.8 \%$ for each classification level, while at $30 \%$ cover, the mean CI was 27.2 to $32.7 \%$ (Fig. 6).

\section{DISCUSSION}

Our study shows that video images can produce both accurate and precise estimates of percent cover of abundant taxa. We found no clear relationship 
between accuracy of identification and abundance of benthic organisms in the samples. Differences in accuracy of identification among regions of the GBR were also small when compared to variation within levels of classification. Inter-observer error did not contribute greatly to the variation in estimates of percent cover of abundant taxa.

These findings are consistent with those of Aronson et al. (1994) and Aronson \& Swanson (1997), who also concluded that differences in cover of abundant taxa on reefs in the western Atlantic, as well as differences in species diversity, could be determined accurately from video transects. On the GBR, mean cover of hard and soft corals and algae on reefs surveyed by the LTMP program was approximately 30, 13 and $46 \%$, respectively (Ninio et al.
Table 2. Comparison of components of observer variability at $10 \%$ cover. Tabulated values are CIs (in \% cover) due to within-observer (W, repeated samples by a single observer) and between-observer (B, among observers over time) variability

\begin{tabular}{|llcccc|}
\hline $\begin{array}{l}\text { Classification } \\
\text { level }\end{array}$ & \multicolumn{1}{c}{ Category } & Label & W & B & Total \\
& & & & & \\
\hline \multirow{5}{*}{ Group } & Soft coral & SC & 1.37 & 0.03 & 1.40 \\
& Hard coral & HC & 0.84 & 0.17 & 1.01 \\
& Algae & ALG & 1.52 & 0.46 & 1.98 \\
& Encrusting non-Acropora & CE & 1.85 & 0.69 & 2.53 \\
& Sub-massive non-Acropora & CS & 1.60 & 0.02 & 1.62 \\
& Branching non-Acropora & CB & 2.66 & 0.25 & 2.91 \\
& Massive non-Acropora & CM & 1.93 & 0.17 & 2.09 \\
& Tabulate Acropora & ACT & 1.38 & 0.00 & 1.38 \\
& Corymbose Acropora & ACO & 2.14 & 0.00 & 2.14 \\
& Digitate Acropora & ACD & 4.7 & 0.22 & 4.93 \\
& Branching Acropora & ACB & 3.12 & 1.30 & 3.93 \\
& Pocilloporidae & POC & 1.11 & 0.03 & 1.15 \\
& Poritidae & POR & 2.58 & 0.00 & 2.58 \\
& Faviidae & FAV & 1.56 & 0.01 & 1.56 \\
& Acroporidae & ACR & 1.88 & 0.01 & 1.89 \\
& Mussidae & MUS & 2.64 & 0.70 & 3.34 \\
\hline
\end{tabular}
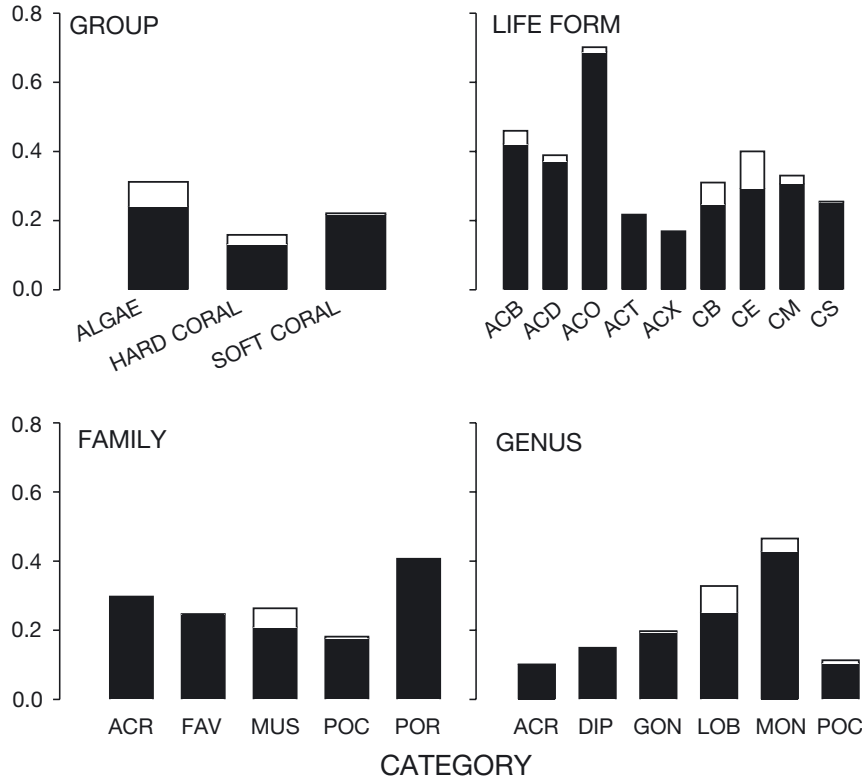

Fig. 5. Relative contribution of between-observer variability (open sections) and within-observer variability (filled sections) to total variability for categories in benthic groups, life forms, families, and genera. Components of observer variability are the SD of estimates of percent cover (based on squareroot transformed data, but retransformed for plotting). Labels for life form are: branching Acropora (ACB), digitate Acropora (ACD), corymbose Acropora (ACO), tabulate Acropora (ACT), bottlebrush Acropora (ACX), branching non-Acropora (CB), encrusting non-Acropora (CE), massive non-Acropora $(\mathrm{CM})$ and sub-massive non-Acropora (CS). Labels for families are: Acroporidae (ACR), Faviidae (FAV), Mussidae (MUS), Pocilloporidae (POC) and Poritidae (POR). Labels for genera are: Acropora (ACR), Diploastrea (DIP), Goniopora (GON), Lobophyllia (LOB), Montipora (MON) and Pocillopora (POC)
2000). At these abundances, we found that observer error would contribute approximately $2 \%$ towards estimates of cover of hard and soft corals and $\pm 4 \%$ to estimates of cover of algae. Similarly, observer errors contribute little to variability in cover estimates for families of hard corals. Maximum cover of families on reefs surveyed by the LTMP ranged from $86 \%$ for the Acroporidae down to $16 \%$ for the Mussidae. At these levels of cover, CIs due to observer errors would be approximately 82 to $90 \%$ for Acroporidae and 13 to $19 \%$ for Mussidae. As cyclones, crown-of-thorns starfish and bleaching frequently cause more than $50 \%$ reduction in cover of hard corals (Oliver et al. 1995, Ninio et al. 2000, Cheal et al. 2002), our study shows that observer error will not limit the effectiveness of underwater video as a method for detecting changes in cover of abundant taxa due to these acute disturbances.

Carleton \& Done (1995) also examined the effect of observer error in estimating cover of benthic groups and life forms of hard coral using underwater video. While precise estimates could be obtained for these broad taxonomic categories, they found that the low resolution of video images made it difficult to identify organisms consistently into finer taxonomic categories (i.e. family, genera and species). However, their transects were filmed from ca. $1 \mathrm{~m}$ above the substratum, whereas the LTMP transects were filmed from a distance of approximately $30 \mathrm{~cm}$. This shorter focal distance improved image quality and may account for our ability to identify organisms to finer levels of classification such as family and genus. 

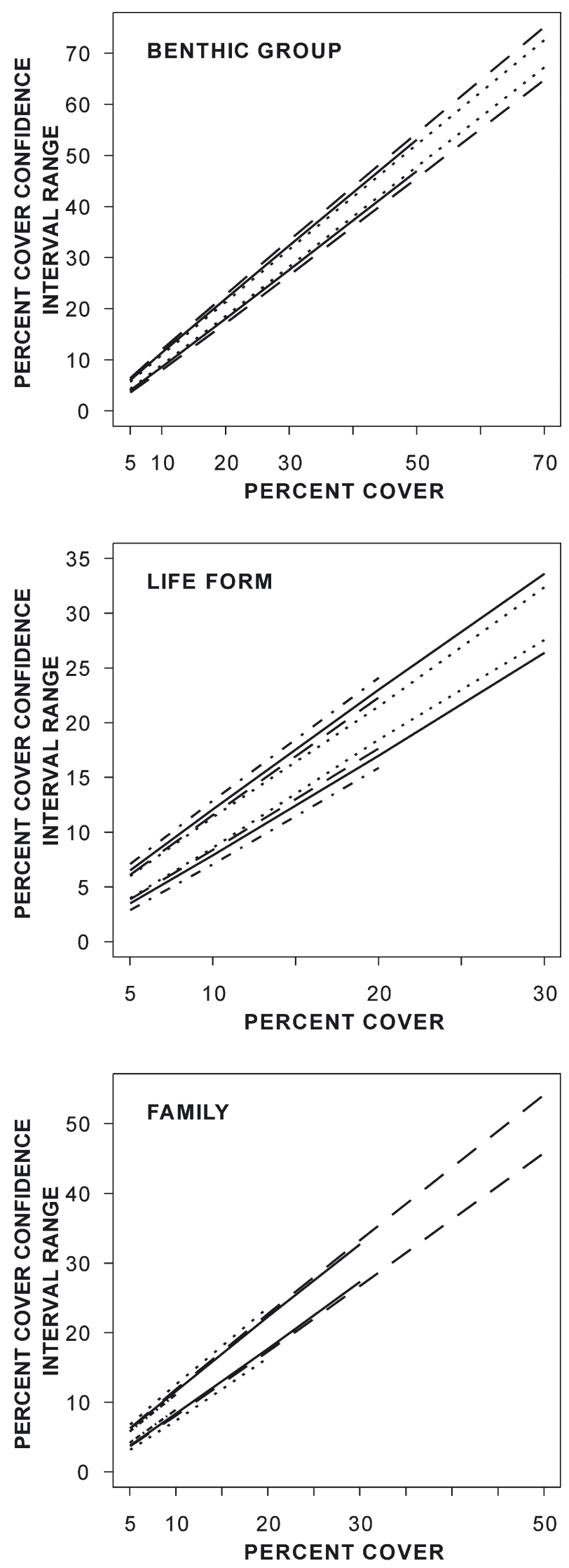

Life forms of hard corals were the least accurate and most variable level of classification. Life forms are often used in studies that aim to provide broad descriptions of benthic communities (Oliver et al. 1995, Sweatman 1997, Cheal et al. 2002). Their use is based on an assumption that life form categories are easy to learn, so require little observer training (Oliver et al. 1995, English et al. 1997). Our study shows that this level of classification was the least accurate. This may be due to $3 \mathrm{D}$ corals appearing as $2 \mathrm{D}$ in video images, reducing the perspective required for classifying them into the different growth forms by shape. Families, genera and species provide more accurate classifications of hard corals by adequately trained observers, and are also more relevant in addressing many ecological questions (Ninio \& Meekan 2002).

We assumed that the marked organisms were identified correctly in the field. To minimise errors, field data were only recorded if the observer was confident of identifications. No discrepancies were found when different observers identified the same marked organisms in the field on at least 100 occasions. However, it is likely that a few errors did occur. For example, in the minutes between filming a transect and identifying the marked organisms underwater, fishes sometimes removed the markers from their territories. Fin kicks by divers and currents may also have caused markers to move on rare occasions. Such occurrences would mean that our estimates of the accuracy of identification of corals from video images are conservative.

When we compared cover estimates from reefs sampled by 2 observers on 3 separate occasions, we found that differences between observers had little effect on mean estimates of cover of abundant taxa. That is, there was little additional variability in estimates of cover by different observers relative to variability from repeated samples taken by a single observer. Between-observer errors had almost no effect on estimates of mean cover for 4 of the 5 families and 5 of the 7 genera. This was in spite of the fact that the observers' experience identifying benthic organisms

Fig. 6. Estimated $95 \%$ CIs associated with observer error for percent cover of benthic group and life form categories, and families. CIs were estimated at 5, 10, 20, 30, 50, and $70 \%$ cover for each category (if they were recorded up to that level of cover in the field) in each classification level. Only those categories with a range cover in the field that was greater than $10 \%$ are represented. Benthic groups: hard coral (....), soft coral $(-)$, and algae (-- -). Life forms: tabulate Acropora ( $\cdots \cdot)$, massive non-Acropora (-), sub-massive non-Acropora (-- ), and branching Acropora $(\cdot-\cdot-)$. Family: Acroporidae $(---)$, Faviidae $(-)$, Poritidae $(\cdots \cdot)$, and Pocilloporidae $(\cdot-\cdot-)$. For example, CI for family Acroporidae at $50 \%$ cover is 46 to $54 \%$ 
ranged from $<1$ to $>3 \mathrm{yr}$ at the beginning of the study. These results indicate that changing observers during the course of a long-term project should have little effect on the quality of the data set, provided that the observers have undergone adequate training and the quality of video images is reasonable. However, this result did not apply to all corals, notably the Montipora (family Acroporidae) and the Lobophyllia (family Mussidae), both of which were rarely encountered. Closer examination showed that classification errors in the genus Montipora were largely due to poor image quality on a single transect where small fragments of this encrusting coral were confused with Porites spp. Interobserver errors in estimates of cover for the genus Lobophyllia could be attributed to a confusion of data codes by one observer.

Variation in estimates of cover among observers resulted not only from differences in identification, but also from uncertainty in delineating margins of organisms and from parallax between the marker point on the face of the video screen and the actual image. A review of 200 points by an independent observer suggested that parallax was the major cause of variation between observers (P. Tomkins pers. comm.), with approximately half the differences in identification of benthic organisms among observers potentially due to this effect.

Since observer error was generally small and its largest component was likely to have been due to random sources such as parallax error, we assume that our measure of intra-observer variability can be applied to other situations. For example, 'placement error' (variation in cover estimates contributed by small scale, $\mathrm{cm}$ to $\mathrm{m}$, differences in positioning of fixed transect tapes; Davidson 1997) and 'sampling sequence' (variation due to analysing a different sub-set of points on any given transect Davidson 1997) will also contain a component of intra-observer variability, as our study shows that the same observer identifying the same points on separate occasions may give different estimates of cover.

Monitoring studies document changes in reef communities. Estimates of cover of taxa examined in this study (i.e. taxa with $>5 \%$ cover on at least 1 reef) were relatively precise, and the observer-error component was small. Spatial differences and temporal trends in these taxa should therefore be well estimated. Many taxa were not sufficiently abundant for observer errors to be estimated reliably relative to total sampling variation. For these less abundant genera and families, trends may not be detected, or may be underestimated, and the contribution of observer error to our ability to detect change in these taxa remains unknown. Large sampling variation in cover estimates of these lessfrequently encountered groups is an inevitable conse- quence of the large-scale and long-term nature of such monitoring studies. The potential to underestimate trends in minor components of the communities needs to be recognised when making inferences about change within these systems. Long-term data on such groups are valuable for understanding shifts in the composition of benthic communities, which could be due to stresses such as elevated temperatures or changes in water quality, and are clearly of interest to reef managers.

Acknowledgements. We thank all members of the LTMP team, Mark Meekan, Greg Coleman, Paula Tomkins, Dan Ryan and the crews of RV 'Harry Messel' for their assistance in this study. This work is a contribution from the CRC Reef Research Centre.

\section{LITERATURE CITED}

Aronson RB, Swanson DW (1997) Video surveys of coral reefs: univariate and multivariate applications. Proc 8th Int Coral Reef Symp 2:1441-1446

Aronson RB, Edmunds PJ, Precht WF, Swanson DW, Levitan DR (1994) Large scale, long-term monitoring of Caribbean coral reefs: simple, quick, inexpensive techniques. Atoll Res Bull 42:1-19

Carleton JH, Done TJ (1995) Quantitative video sampling of coral reef benthos: large scale application. Coral Reefs 14: $35-46$

Cheal AJ, Coleman G, Delean S, Miller IR, Osborne K, Sweatman $H$ (2002) Responses of coral and fish assemblages to a severe but short-lived tropical cyclone on the Great Barrier Reef, Australia. Coral Reefs 21:131-142

Connell JH (1997) Disturbance and recovery of coral communities. Coral Reefs 16(Suppl):S101-S113

Dahl AL (1977) Monitoring man's impact on Pacific Island reefs. Proc 3rd Int Coral Reef Symp 2:571-575

Davidson J (1997) Optimising the use of a video transect technique for the monitoring and rapid ecological assessment of tropical benthic communities. MSc thesis, James Cook University, Townsville

Done TJ (1981) Photogrammetry in coral ecology: a technique for the study of change in coral communities. Proc 4th Int Coral Reef Symp 2:315-319

English S, Wilkinson C, Baker V (1997) Survey manual for tropical marine resources, 2nd edn. Australian Institute of Marine Science, Townsville

Hastie TJ, Tibshirani RJ (1990) Generalized additive models. Chapman \& Hall, London

Hughes TP (1994) Catastrophes, phase shifts, and large-scale degradation of a Caribbean coral reef. Science 265: $1547-1551$

Leonard GH, Clark RP (1993) Point quadrat versus video transect estimates of the cover of benthic red algae. Mar Ecol Prog Ser 101:203-208

McCullagh P, Nelder JA (1989) Generalized linear models, 2nd edn. Chapman \& Hall, London

Ninio R, Meekan MG (2002) Spatial patterns in benthic communities and the dynamics of a mosaic ecosystem on the Great Barrier Reef, Australia. Coral Reefs 21:95-103

Ninio R, Meekan MG, Done TJ, Sweatman H (2000) Temporal patterns in coral assemblages on the Great Barrier Reef 
from local to large spatial scales. Mar Ecol Prog Ser 194: $65-74$

Oliver J, De'ath G, Done T, Williams D, Furnas M, Moran P (1995) Long-term monitoring of the Great Barrier Reef. Status Report No. 1. Australian Institute of Marine Science, Townsville

Page C, Coleman G, Ninio R, Osborne K (2001) Surveys of benthic reef communities using underwater video. Long Term Monitoring of the Great Barrier Reef, Standard Operational Procedure No. 2. Australian Institute of Marine Science, Townsville

Editorial responsibility: Otto Kinne (Editor), Oldendorf/Luhe, Germany
Pinheiro JC, Bates DM (2000) Mixed-effects models in S and S-Plus. Springer-Verlag, New York

Sweatman H (1997) Long-term monitoring of the Great Barrier Reef. Status Report No. 2, Australian Institute of Marine Science, Townsville

Sweatman H, Cheal A, Coleman G, Fitzpatrick B and 7 others (2000) Long-term monitoring of the Great Barrier Reef. Status Report No. 4. Australian Institute of Marine Science, Townsville

Wilkinson CR (2000) Status of coral reefs of the world: 2000. Australian Institute of Marine Science, Townsville

Submitted: March 26, 2002; Accepted: October 11, 2003

Proofs received from author(s): November 28, 2003 